\title{
Análise do fator de proteção solar em extratos glicólicos e óleos fixos de plantas da Amazônia
}

\author{
P. H. S. da Silva ${ }^{1}$, R.Z. Coelho', G.F. da Silva ${ }^{2}$, R. B. de Castilho' ${ }^{2}$, P.M. Albuquerque ${ }^{1}$ \\ ${ }^{1}$ Universidade do Estado do Amazonas, Escola Superior de Tecnologia \\ ${ }^{2}$ Universidade Federal do Amazonas, Departamento de Química \\ E-mail para contato: pedroenrique_soares@hotmail.com
}

\begin{abstract}
RESUMO - O fator de proteção solar, FPS, é uma propriedade presente em substâncias com capacidade de absorver radiação em determinado comprimento de onda. Os experimentos foram realizados pelo processo in vitro através da análise espectrofotométrica de soluções, com diferentes concentrações e em diferentes comprimentos de onda, preparadas a partir de extratos glicólicos e óleos fixos. Os valores de FPS foram estimados através dos dados obtidos em análise espectrofotométrica relacionando-os com o método in vivo de Mansur e usando a razão das áreas sob a curva UVA em relação a UVB. O extrato glicólico de açaí e o óleo fixo e buriti apresentaram os maiores potenciais, entre os óleos e extratos analisados, para serem usados em formulações de fotoprotetores.
\end{abstract}

\section{INTRODUÇÃO}

A Amazônia é uma região rica em espécies vegetais. Grande parte dessas plantas pode ser usada para o tratamento de diversas doenças. Nesse experimento optou-se por usar plantas nativas da Amazônia para analisar sua capacidade de uso em fotoprotetores.

Filtros solares são substâncias capazes de absorver, refletir ou refratar a radiação ultravioleta e assim minimizar os efeitos da exposição direta da luz solar (Giokas et al., 2005). Atualmente, é uma tendência do mercado o desenvolvimento de produtos com componentes de origem natural, em especial de origem vegetal, de forma a explorar e evidenciar a biodiversidade brasileira (Biavatti et al., 2007).

Pesquisas têm mostrado que a radiação UV danifica o material genético, oxida os lipídios e produz perigosos radicais livres, causa inflamação, rompe a comunicação celular, modifica a expressão dos genes em resposta ao estresse e enfraquece a resposta imune da pele (Rangarajan e Zatz, 2003).

O presente projeto tem como principal proposta realizar estudos espectrofotométricos utilizando diversos derivados vegetais presentes na Amazônia, como os óleos fixos e os extratos glicólicos de açaí (Euterpe oleracea), andiroba (Carapa guianensis), copaíba (Copaifera langsdorfii), mulateiro (Calycophyllum spruceanum), castanha do pará (Bertholletia excelsa), crajiru (Arrabidea chica verlot), buriti (Mauritia flexuosa), Guaraná (Paulinia cupana kunth), Cupuaçu (Theobroma grandiflorum), amor crescido (Portulaca pilosa), noni (Morinda citrifolia), murumuru (Astrocaryum murumuru), maracujá (Passiflora 


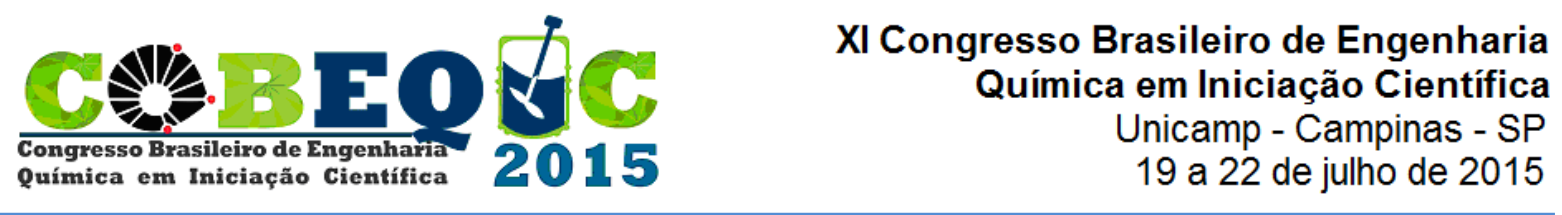

alata dryand) que possui função comprovada pela ciência de benefícios oferecidos para os seres humanos e formulações cosméticas elaboradas em conjunto com os demais membros do grupo de pesquisa, com o objetivo de determinar o potencial fotoprotetor de compostos naturais presentes na Amazônia, utilizando os métodos conhecidos capazes de indicar a eficácia protetora frente a radiação ultravioleta desenvolvendo uma qualificação de FPS que possua abrangência na radiação UVA e UVB.

\section{MATERIAL E MÉTODOS}

\subsection{Obtenção e secagem dos extratos glicólicos e óleos fixos}

Os extratos glicólicos e óleos fixos foram obtidos comercialmente da empresa Essências da Amazônia, devidamente certificados e com seus laudos de análise. A concentração do conteúdo vegetal foi determinada secando-se os extratos em estufa, a $100^{\circ} \mathrm{C}$, medindo-se a variação na massa a cada 30 minutos, até massa seca constante.

\subsection{Preparo das soluções dos extratos, óleos e padrões}

A partir dos extratos glicólicos e óleos fixos das plantas já citadas preparou-se soluções nas concentrações de $1 \%, 3 \%, 6 \%$ e $9 \% \mathrm{~m} / \mathrm{m}$, em etanol P.A., após feitas as soluções as mesmas foram analisadas com o intuito de realizar uma triagem para a obtenção da concentração mais adequada para a realização do experimento e para o uso em formulações cosméticas para proteção solar. Para o padrão, Benzofenona, a concentração usada foi de $0,00125 \%$, essa concentração foi escolhida após análise para que fosse respeitada a lei de Beer-Lambert.

\subsection{Determinação do Fator de Proteção Solar e razão UVA/UVB}

Para a determinação do FPS e da razão UVA/UVB analisou-se as soluções em um espectrofotômetro, Shimadzu UV-1800, no qual realizou-se uma varredura das absorbâncias das soluções nos comprimentos de onda compreendidos entre $280 \mathrm{~nm}$ e $400 \mathrm{~nm}$, com intervalos de $1 \mathrm{~nm}$. Com os dados obtidos, os FPS foram calculados para a concentração de $1 \%$, usando-se a equação 1, conforme feito por (Mansur et al., 1986) e a razão das áreas sob a curva UVA em relação a curva UVB (Springsteen et al., 1999), equação 2. Foram classificados segundo o Sistema Boot's Star Racing relacionado a razão UVA/UVB como mostrado na tabela 1 .

Tabela 1 - Sistema Boot's Star Rating relacionado a razão UVA/UVB

\begin{tabular}{lll}
\hline Razão UVA & Estrelas & Descrição \\
\hline 0,0 até $<0,2$ & - & Muito baixa \\
0,2 até $<0,4$ & $*$ & Moderada \\
0,4 até $<0,6$ & $* *$ & Boa \\
0,6 até $<0,8$ & $* * *$ & Superior \\
0,8 até $<0,9$ & $* * * *$ & Máxima \\
$\geq 0,9$ & $* * * *$ & Ultra \\
\hline
\end{tabular}


$F P S=F C x \sum_{290}^{320} x E(\lambda) \times I(\lambda) \times A b s(\lambda)$

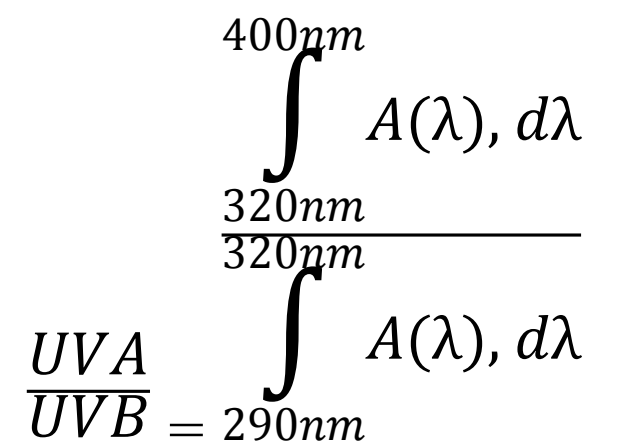

(2)

\section{RESULTADOS E DISCUSSÕES}

\subsection{Concentração e rendimento dos extratos}

Os valores das concentrações e dos rendimentos dos extratos usados nas análises estão expostos na tabela 2 .

Tabela 2 - Rendimento e concentração dos extratos pesquisados

\begin{tabular}{|c|c|c|}
\hline Extrato & $\begin{array}{l}\text { Rendimento } \\
(\%)\end{array}$ & Concentração(mg/ml) \\
\hline Guaraná & 12,25 & 122,5 \\
\hline Amor Crescido & 7,3 & 0,73 \\
\hline Murumuru & 6,406 & 64,1 \\
\hline Copaíba & 6,194 & 61,9 \\
\hline Buriti & 5,95 & 59,5 \\
\hline Cupuaçu & 5,466 & 54,66 \\
\hline Crajiru & 4,382 & 43,8 \\
\hline Andiroba & 4,206 & 42,06 \\
\hline Noni & 2,048 & 20,5 \\
\hline Açaí & 1 & 10 \\
\hline Castanha do Pará & 0,65 & 6,5 \\
\hline Mulateiro & 0,15 & 1,5 \\
\hline
\end{tabular}

\subsection{Fator de Proteção Solar e Razão UVA/UVB}


Após análise das soluções nas diferentes concentrações, os valores foram ajustados para $1 \% \mathrm{~m} / \mathrm{m}$ considerado sua utilização em formulações cosméticas que podem ser observados na tabela 3. Foram obtidos os espectros absorção para cada amostra analisada e a eficácia da proteção oferecida pelo produto utilizando os métodos da razão da UVA/UVB. Com base nos valores obtidos e expostos na tabela 3:

Tabela 3 - Extratos, óleos e padrões, e seus respectivos FPS's, razões UVA/UVB e classificações, na concentração de $1 \% \mathrm{~m} / \mathrm{m}$

\begin{tabular}{lccccc} 
Planta & Tipo & FPS & Classificação & UVA/UVB & Classificação \\
\hline Benzofenona & Padrão & $\mathbf{1 5 6 9 , 3 7}$ & Muito alta & $\mathbf{0 , 6 1 6}$ & Superior \\
Buriti* & Óleo & 45,007 & Muito alta & 0,893 & Máxima \\
Buriti** & Óleo & 27,598 & Muito alta & 0,667 & Superior \\
Copaíba & Óleo & 24,397 & Muito alta & 0,799 & Superior \\
Andiroba & Óleo & 19,962 & Alta & 0,626 & Superior \\
Açaí & Extrato & 12,313 & Alta & 0,625 & Superior \\
Amor crescido & Extrato & 8,904 & Moderada & 0,931 & Ultra \\
Murumuru & Extrato & 6,144 & Moderada & 1,013 & Ultra \\
Copaíba & Extrato & 5,72 & Baixa & 0,986 & Ultra \\
Crajiru & Extrato & 5,275 & Baixa & 0,806 & Máxima \\
Noni & Extrato & 4,95 & Baixa & 1,009 & Ultra \\
Guaraná & Extrato & 4,068 & Baixa & 1,243 & Ultra \\
Mulateiro & Extrato & 3,836 & Baixa & 1,079 & Ultra \\
Andiroba & Extrato & 2,366 & Baixa & 0,805 & Máxima \\
Buriti & Extrato & 1,951 & - & 1,412 & Ultra \\
Maracujá & Extrato & 0,601 & - & 1,094 & Ultra \\
Castanha do Pará & Extrato & 0,391 & - & 1,324 & Ultra \\
Cupuaçu & Extrato & 0,312 & - & 0,964 & Ultra \\
\hline
\end{tabular}

FPS - Fator de proteção solar; UVA -Radiação Ultravioleta (320nm à 400nm); UVB - Radiação Ultravioleta $(280 \mathrm{~nm}$ à $320 \mathrm{~nm})$. * Produto adquirido na empresa Aboriti; ** Produto adquirido na empresa Essências da Amazônia.

Razão UVA/UVB "Ultra": Castanha, copaíba, amor crescido, noni, murumuru, mulateiro, cupuaçu, guaraná, maracujá e buriti apresentaram uma boa razão entre os comprimentos de onda analisados, porém de todos esses apenas o amor crescido apresentou o maior FPS, considerado "moderado" na região do UVB, segundo a legislação brasileira, RDC 


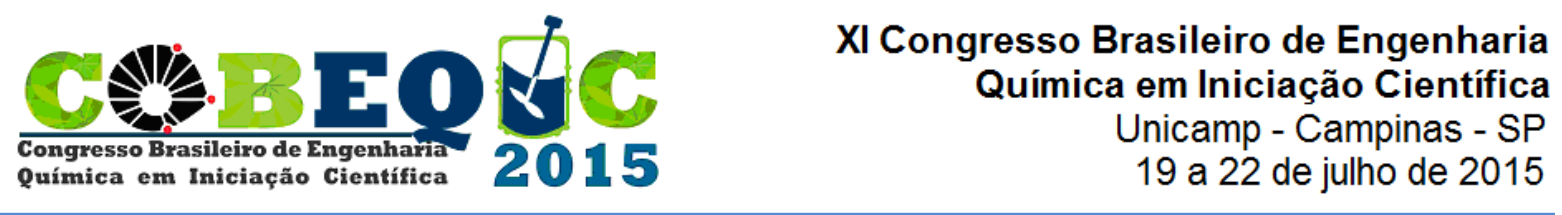

237 de 22/08/2002 (Brasil, 2002), enquanto copaíba, noni, murumuru, mulateiro e guaraná são classificados como proteção "baixa". E por fim aqueles que obtiveram um FPS inferior a 2, como é o caso da castanha cupuaçu, maracujá e buriti não são indicados para uso em fotoprotetores.

Razão UVA/UVB "Máxima": Crajiru, andiroba, e óleo de buriti* estão nesta categoria segundo o sistema Boot's Star Rating, onde o crajiru e a andiroba possuem um FPS "baixo" na região do UVB, o que difere em muito do óleo de buriti que apresentou um FPS "muito alto" segundo a RDC 237 de 22/08/2002 (Brasil, 2002).

Razão UVA/UVB "Superior": Óleo de buriti**, óleo de andiroba, óleo de copaíba e açaí são classificados como "Superior". Os óleos de buriti** e copaíba apresentaram um FPS "muito alto" enquanto o açaí e o óleo de andiroba apresentaram um FPS "alto" segundo a RDC 237 de 22/08/2002 (Brasil, 2002). Nota-se que o óleo de andiroba apresentou atividade, porém segundo a literatura não deveria ter apresentado, tal fato pode ser explicado pela má conservação do óleo utilizado.

No geral os extratos e óleos apresentaram ótimas razões, porém só são considerados apropriados para o uso em formulações fotoprotetoras, caso possuam também um valor de FPS considerado, pelo menos, "baixo", segundo a RDC 237 de 22/08/2002 (Brasil, 2002).

\section{CONCLUSÕES}

$\mathrm{Na}$ concentração utilizada os extratos e óleos que segundo a literatura poderiam ser usados para a produção de fotoprotetores seriam todos aqueles que apresentaram um FPS acima de 2, com dois sendo o menor nível de proteção que deve ser oferecido. Neste caso os óleos e extratos que não se mostraram adequados para o uso na formulação de fotoprotetores foram os extratos de crajiru, castanha do Pará, cupuaçu, maracujá e buriti, pois apresentaram um FPS inferior a 2 que é o mínimo exigido pela Agência Nacional de Vigilância Sanitária ANVISA. Pode-se notar que os óleos, em geral, mostraram-se mais adequados ao uso na formulação de fotoprotetores, pois apresentaram altos valores de FPS e boas razões UVA/UVB.

A fotoestabilidade dos óleos e extratos analisados será avaliada em estudos futuros.

\section{NOMENCLATURA}

$\operatorname{Abs}(\lambda)=$ absorbância da solução no comprimento de onda $\lambda$.

$\operatorname{EE}(\lambda)=$ efeito eritemogênico da radiação de comprimento de onda $\lambda$.

$\mathrm{FC}=$ Fator de correção.

$\mathrm{I}(\lambda)=$ intensidade do sol no comprimento de onda $\lambda$.

\section{REFERÊNCIAS}


BIAVATTI, M. W. MARENSI, V.; LEITE, S. N; Reis, A. Ethnopharmacognostic survey on botanical compendia for potential cosmeceutic species from Atlantic Forest. Br. J. of Pharma., v. 17, n. 4, p. 640-653, 2007.

Brasil. Agência Nacional de Vigilância Sanitária. Resolução RDC no 237, de 22 de agosto de 2002. Aprova o Regulamento Técnico sobre Protetores Solares em Cosméticos. Diário Oficial da União, n 163, 23 de agosto de 2002. Seção 1E. p. 40.

GIOKAS, D. L.;SAKKAS, V. A.; ALBANIS, T. A.; LAMPROPOULOU, D. A. Determination of UV-filter residues in bathing waters by liquid chromatography UVdiode array and gas chromatography-mass spectrometry after micelle mediated extraction-solvent back extraction. J. of Chroma. A, v. 1077, n. 1, p. 19-27, jun. 2005.

MANSUR, J. de S.; BREDER, M. N. R.; MANSUR, M. C.; AZULAY, R. D. Determinação do fator de proteção solar por espectrofotometria. An. Br. Derm., v. 61, n. 3, p. 121124, 1986.

RANGARAJAN, M.; ZATZ, J. L. Effect of formulation on the topical delivery of alphatocophero. J. Cosmet Sci., v. 54, n. 2, p. 161-74, 2003.

SPRINGSTEEN, A.; YUREK, R.; FRAZIER, M.; CARR, K. F. In vitro measurement of sun protection factor of sunscreens by diffuse transmittance . A. Chim. A., v. 380, p. 155164, 1999. 